\title{
SYNTHESES AND ANTIOXIDANT ACTIVITIES OF SOME HYDROXY DIMETHOXY CHALCONE DERIVATIVES
}

\author{
Elfi Susanti VH ${ }^{1}$, Sabirin Matsjeh ${ }^{2}$, Mustofa ${ }^{3}$, Tri Redjeki ${ }^{1}$ \\ and Tutik Dwi Wahyuningsih ${ }^{2}$
}

\begin{abstract}
${ }^{1}$ Dept. Chemistry FKIP Univ. Sebelas Maret, Jl. Ir Sutami 36A Surakarta Indonesia, 57126 ${ }^{2}$ Dept. Chemistry FMIPA Univ. Gadjah Mada, Jl Sekip Utara, Yogyakarta Indonesia 55281 ${ }^{3}$ Faculty of Medicine, Univ. Gadjah Mada, Jl. Sekip Utara Yogyakarta Indonesia, 55281

Submitted: 20-08-2013

Revised: $15-11-2013$

Accepted: 04-12-2013

*Corresponding author Elfi Susanti VH

Email :

elsantivh@yahoo.com
\end{abstract}

\section{INTRODUCTION}

Hydroxy chalcone known as intermediates for the synthesis of a variety of flavonoids, such as flavones, isoflavones, flavanones and flavonols. This compound has a skeletal system of 1,3-diaryl-1-one, has pharmacological activity, such as anticancer (Patil, et al., 2009), antimicrobial (Mandge, et al, 2007 and Prasad, et al, 2008), insecticides (Nalwar, et al., 2009) and antioxidants (Belsare, et al., 2011). Synthesis is the best alternative for obtaining chalcone, because stable chalcone difficult to obtain due to the existence of the plant enzyme chalcone synthetase (CSH) which converts chalcone into flavanones (Mandge, et al., 2007).

Chalcone synthesis method most widely developed is Claisen-Schmidt condensation. Prasad et al. (2008) have synthesized chalcone derivative 12 by Claisen-Schmidt condensation of acetophenone derivatives and benzaldehyde derivatives using $\mathrm{KOH}$ as catalyst in ethanol. The study found that compounds with hydroxy and methoxy groups showed better antibacterial activity than chalcone without methoxy or hydroxy groups. Four chalcone derivative (4-dimethyl amino chalcone, 2hydroxy-4-dimethyl amino chalcone, and 2hydroxy chalcone) has been synthesized in this way using alkaline catalyst ( $\mathrm{KOH}$ 60\%) in ethanol (Mandge et al., 2007).
In this study 4 hydroxy chalcone derivatives were synthesized by ClaisenSchmidt condensation from 3,4-dimethoxybenzaldehyde using grinding and conventional method, then analyzed its antioxidant activity. Reaction in grinding technique are simple due to reactions are initiated by grinding, occurs through generation of local heat by grinding of crystals of substrate and reagent by mortar and pestle (Zangade, et al., 2011). This method is used to develop chalcone synthesis method that is more friendly to the environment and high yielding.

Many studies have found that chacone exhibit various biological activities, such as antiviral, anti-inflammatory, and anticancer. Bioactivity is generally attributed to its antioxidant properties of chalcone, namely their ability to protect cells against the damaging effects of reactive oxygen species, such as singlet oxygen, superoxide, peroxy radicals, and hydroxyl radicals. These free radicals are involved in the process of a number of diseases, such as cancer, aging, atherosclerosis, inflammation and neurodegenerative diseases (Parkinson's and Alzheimer's), as well as hearing loss. Imbalance between antioxidants and reactive oxygen species in oxidative stress causes damage to cells (Warner, et al., 2004.) 
Antioxidants react with free radicals at a higher speed than the substrate. Free radicals can attack a variety of targets including lipids, fats and proteins, so it is believed that free radicals damage the organism, causing illness, aging and toxic (Wright, et al., 2001). Hydroxy chalcone can capture free radicals directly. These compounds are oxidized by radicals, forming less reactive radicals. In other words, hydroxy chalcone stabilize reactive oxygen species by reacting with radicals. Hydroxy chalcone high reactivity causes radical becomes inactive (Narayana, et al., 2001). For the purpose of the development of antioxidant agents, we needed to modify the structure or substitute suitable groups in the structure of hydroxy chalcone to improve antioxidant activities. Therefore, we synthesized a series of hydroxy-3,4-dimethoxy chalcone and examined their antioxidant activities.

\section{MATERIAL AND METHODS}

Synthesis of hydroxy dimethoxy chalcone using conventional method

A mixture of hydroxyacetophenone (0.01 mole) and 3,4-dimethoxybenzaldehyde derivatives $(0.01 \mathrm{~mole})$ were stirred in ethanol $(15 \mathrm{~mL})$ and then an aqueous of sodium hydroxide $50 \%(12 \mathrm{~mL})$ were added. The reaction mixture was stirred at room temperature and left at room temperature for $24 \mathrm{~h}$, poured into iced water, acidified with cold $\mathrm{HCl}(10 \%)$, and extracted with ether $(3 \times 25 \mathrm{~mL})$. The organic layer was washed with water, dried by addition over anhydrous $\mathrm{Na}_{2} \mathrm{SO}_{4}$. The solvent was evaporated by rotary evaporator. Purification the compound was done by Column chromatography on a silica gel column (n-hexane:acetone, 7:3), recrystalized by ethanol and characterized by UV Vis, IR, ${ }^{1} \mathrm{H}$ NMR and ${ }^{13} \mathrm{C}$ NMR Spectroscopy. Four kinds of hydroxyl 3,4-dimethoxy chalcone derivatives were synthesized using base material 2-hydroxy acetophenone, 2,4-dihydroxy acetophenone, 2,5-dihydroxy acetophenone and 2,6-dihydroxy acetophenone.

\section{Synthesis of hydroxy dimethoxy chalcone using grinding method}

The hydroxyacetophenones (5mmol), 3,4-dimethoxybenzaldehyde (10 mmol) and solid $\mathrm{NaOH}(20 \mathrm{mmol})$ was ground with a mortar and pestle at room temperature for $15 \mathrm{~min}$. The obtained solid mixture was diluted with cold water, added cold $\mathrm{HCl}(10 \%)$ until $\mathrm{pH} 2-4$, and extracted with ether. The ether layer was washed with water, dried by over anhydrous $\mathrm{Na}_{2} \mathrm{SO}_{4}$ and evaporated. Purification using by Column chromatography on a silica gel column (n-hexane:acetone, 6:4), followed by recrystalization. Identification of chalcone structure using by UV Vis, IR, NMR Spectroscopy.

\section{Antioxidant activity of compounds was performed by DPPH method.}

In vitro antioxidant activity of compounds synthesized done by DPPH method (Belsare et al., 2010), a method used to determine the activity of free radicals capture. Samples were dissolved in methanol and prepared in various concentrations $(0,10,30$, 50 and $70 \mathrm{ppm})$. Each solution is put into a test tube. Into each tube was added $500 \mu \mathrm{L}$ solution of $1 \mathrm{mM}$ DPPH in methanol, refined to $5.0 \mathrm{~mL}$, and then incubated at $37^{\circ} \mathrm{C}$ for $30 \mathrm{~min}$. The solution was measured at $\lambda 515 \mathrm{~nm}$. Positive controls used vitamin C. Each measurement is done 3times. Capture of free radicals by DPPH was calculated with the equation:

Activity $(\% \mathrm{DPPH}$ reduction $)=[(\mathrm{A}-\mathrm{Ax}) / \mathrm{A}] \mathrm{x}$ $100 \%$

where $\mathrm{A}=$ absorbance of $\mathrm{DPPH}$ solution in methanol, $\mathrm{Ax}=$ absorbance of DPPH solution with sample extracts. IC50 is defined as the sample concentration that showed $50 \%$ capture of radical activity, determined from the relationship graph with the concentration of the antioxidant activity.

\section{RESULTS AND DISCUSSION}

The Claisen-Schmidt condensation reaction is an important method for synthesis of chalcone. The synthesis of hydroxy dimethoxy chalcone is a single step method. The yield of each chalcone synthesized could be seen in Table I. Synthesis of the hydroxy dimethoxy chalcone using grinding method is better than the conventional method. The synthesis using grinding method require a low concentration base, shorter reaction (15min) and higher yield (70-84\%). 


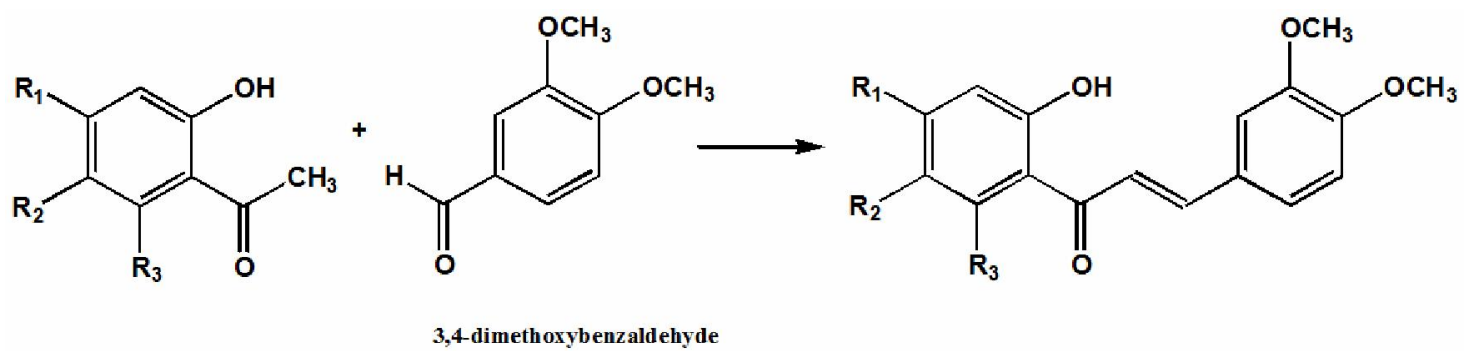

2'-hydroxy-3,4-dimethoxy chalcone: $\mathrm{R}_{1}=\mathrm{R}_{2}=\mathrm{R}_{3}=\mathrm{H} ; \quad$ 2',4'-dihydroxy-3,4-dimethoxy chalcone: $\mathrm{R}_{1}=\mathrm{OH}$,

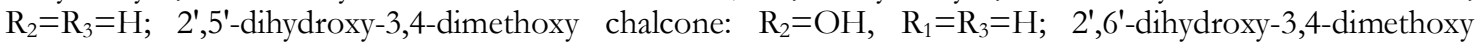
chalcone: $\mathrm{R}_{3}=\mathrm{OH}, \mathrm{R}_{1}=\mathrm{R}_{2}=\mathrm{H}$

Figure 1. Scheme of synthesis hydroxyl dimethoxy chalcone derivatives.

Table I. Yield of derivatives of hydroxy chalcone synthesized

\begin{tabular}{llcc}
\hline \multirow{2}{*}{ No } & \multirow{2}{*}{ Compound } & \multicolumn{2}{c}{ Yield (\%) } \\
\cline { 3 - 4 } & & conventional & grinding \\
\hline 1. & 2'-hydroxy-3,4-dimethoxychalcone & 75 & - \\
2. & 2',4'-dihydroxy-3,4-dimethoxychalcone & 40 & 84 \\
3. & 2',5'-dihydroxy-3,4-dimethoxychalcone & 65 & 73 \\
4. & 2',6'-dihydroxy-3,4-dimethoxychalcone & 65 & 70 \\
\hline
\end{tabular}

Table II. IC 50 of derivatives of hydroxy chalcone synthesized

\begin{tabular}{llc}
\hline No & Compound & IC $\mathbf{5 0}(\boldsymbol{\mu g} / \mathbf{m L})$ \\
\hline 1. & 2'-hydroxy-3,4-dimethoxychalcone & 975 \\
2. & 2',4'-dihydroxy-3,4-dimethoxychalcone & 1402.9 \\
3. & 2',5'-dihydroxy-3,4-dimethoxychalcone & 7.34 \\
4. & 2',6'-dihydroxy-3,4-dimethoxychalcone & 1058 \\
\hline
\end{tabular}

The structure of the synthesized compounds was confirmed by IR, ${ }^{1} \mathrm{H}-\mathrm{NMR}$ and ${ }^{13} \mathrm{C}-\mathrm{NMR}$.

\section{2'-hydroxy-3,4-dimethoxy chalcone}

The IR peak at $3549 \mathrm{~cm}^{-1}$ suggesting the presence of $-\mathrm{OH}$ group The IR peak at $1627 \mathrm{~cm}^{-1}$ suggesting the presence of $\mathrm{C}=\mathrm{O}(\mathrm{Str})$ group. The IR peak at $3078 \mathrm{~cm}^{-1}$ indicates the presence of $\mathrm{C}-\mathrm{H}$ aromatic. The IR peak at $2931 \mathrm{~cm}^{-1}$ indicates the presence of C-H aliphatic. The IR peak at $1026 \mathrm{~cm}^{-1}$ indicates the presence of $\mathrm{C}-\mathrm{O}$. The ${ }^{1} \mathrm{H}-\mathrm{NMR}$ spectrum of 2-hydroxy-3,4-dimethoxy chalcone (Figure 2) displayed multiplet due to overlapping of signal for two methoxyl groups at $\delta 3.91$ integrated for 6 protons. The phenolic $-\mathrm{OH}$ signal was observed at $\delta$ 12.89. The three aromatic proton of the ring $\mathrm{B}$ were observed at $\delta 6.94(1 \mathrm{H}, \mathrm{C}-2) ; \delta 7.0(1 \mathrm{H}, \mathrm{C}-6)$; and $7.2(1 \mathrm{H}$, $\mathrm{C}-5)$. Four aromatic proton of the ring $\mathrm{A}$ were observed at $\delta 7.4\left(1 \mathrm{H}, \mathrm{C}-3^{\prime}\right) ; 7.5\left(1 \mathrm{H}, \mathrm{C}-5^{\prime}\right)$; $7.90\left(1 \mathrm{H}, \mathrm{C}-4^{\prime}\right)$; and 7.92 (1H, C-6').

The ${ }^{13} \mathrm{C}$-NMR spectrum of 2-hydroxy3,4-dimethoxy chalcone (Figure 3) indicated the presence of 16 signals attributed to 17 different carbons. The signal for methyl carbons were overlapping with each other at 56,01. The spectrum indicated the presence five quarternary carbon at $\delta \delta 163.5\left(\mathrm{C}-2^{1}\right), 151.8$ (C-3), 149.3 (C-4), 127.5 (C-1), dan 120,1 (C-1'), dan 9 karbon metin pada $\delta 145.6\left(\mathrm{C}-4^{\prime}\right)$, 136.1 (C- $\alpha), 129.5$ (C-6'), 123.5 (C- $\beta), 118.7$ 


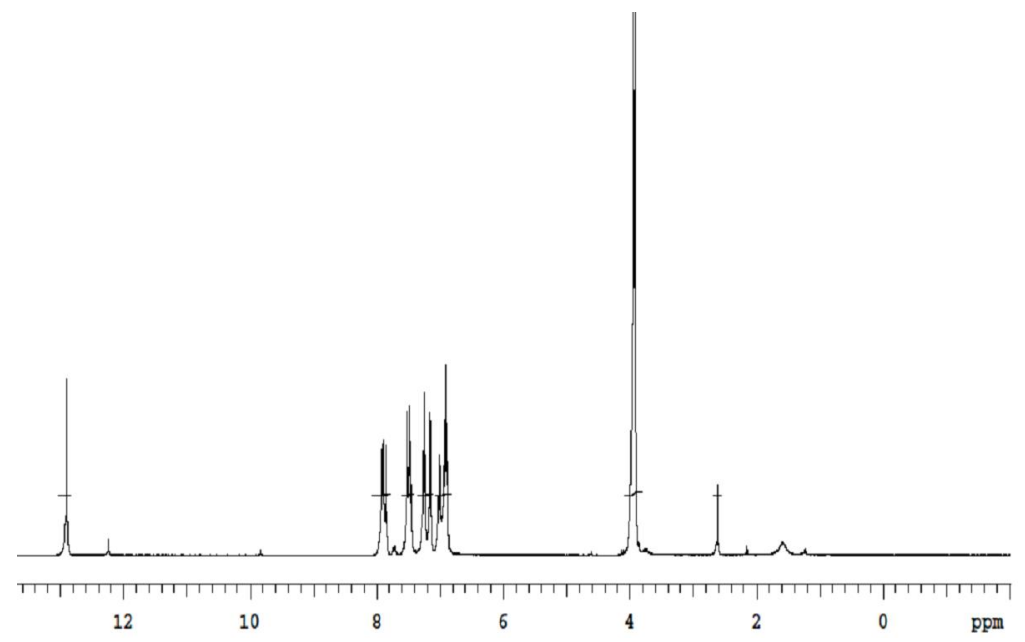

Figure 2. ${ }^{1} \mathrm{H}$ NMR Spectrum of 2'-hydroxy-3,4-dimethoxy chalcone

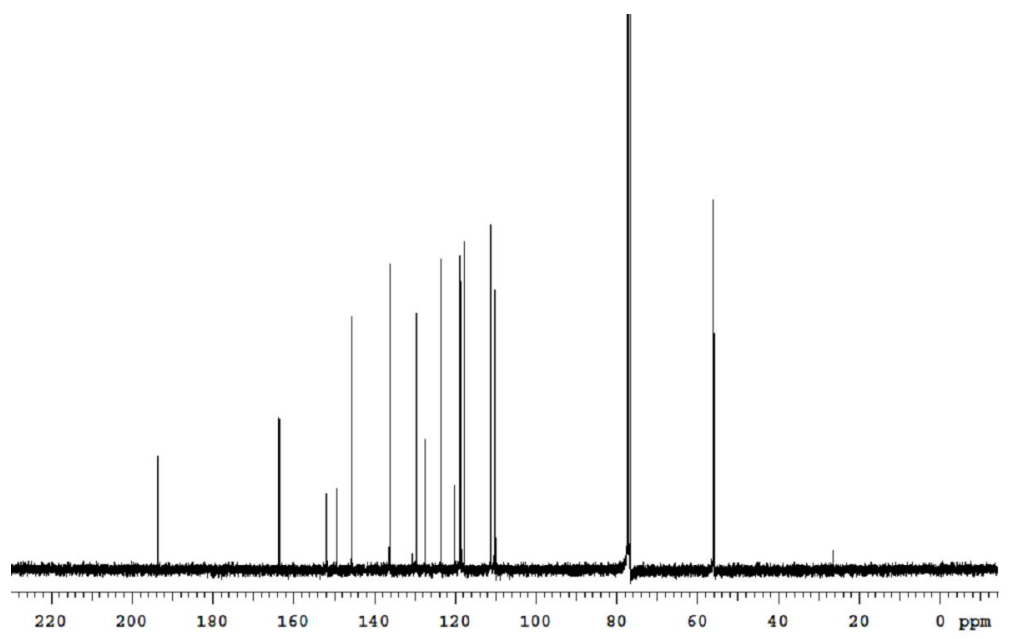

Figure 3. ${ }^{13} \mathrm{C}$ NMR Spectrum of 2'-hydroxy-3,4-dimethoxy chalcone

(C-6), 118.5 (C-5'), 117 (C-3'), 111 (C-2), 110 (C-5), and 9 methine carbons at $\delta 145.6$ $\left(\mathrm{C}-4^{\prime}\right), 136.1(\mathrm{C}-\alpha), 129.5\left(\mathrm{C}-6^{\prime}\right), 123.5(\mathrm{C}-\beta)$, 118.7 (C-6), 118.5 (C-5'), 117 (C-3'), 111 (C-2), 110 (C-5). Based on the above spectral evidences, it can be concluded that compound (1) characterized as 2'-hydroxy-3,4-dimethoxy chalcone.

\section{2',4'-dihydroxy-3,4-dimethoxy chalcone}

The IR absorption spectrum band at $3410 \mathrm{~cm}^{-1}$ indicated that the presence of hydroxyl group, and a band at $1674 \mathrm{~cm}^{-1}$ and
$1589 \mathrm{~cm}^{-1}$ showed the presence of a conjugated carbonyl group. The IR peak at $3086 \mathrm{~cm}^{-1}$ indicates the presence of $\mathrm{C}-\mathrm{H}$ aromatic. The IR peak at $2939 \mathrm{~cm}^{-1}$ indicates the presence of $\mathrm{C}-\mathrm{H}$ aliphatic. The IR peak at $1026 \mathrm{~cm}^{-1}$ indicates the presence of $\mathrm{C}-\mathrm{O}$.

The ${ }^{1} \mathrm{H}-\mathrm{NMR}$ spectrum of compound (Figure 4) displayed the presence of two methoxyl groups in the $\mathrm{B}$ ring at $\delta 3.85$ and 3.86, integrating for 6 protons. The phenolic -OH signal was observed at $\delta$ 4.6. The olefinic proton of $\alpha, \beta$-unsaturated ketone were clearly observed at $\delta 7.5(1 \mathrm{H}, \mathrm{H}-\alpha)$ and 


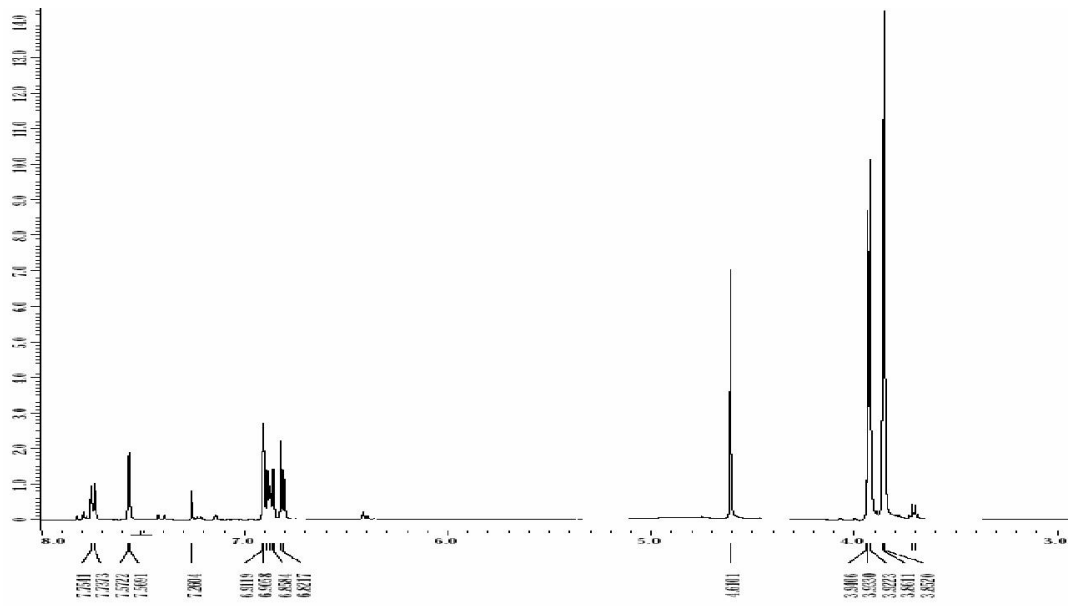

Figure 4. ${ }^{1} \mathrm{H}$ NMR Spectrum of 2',4'-dihydroxy 3,4-dimethoxy chalcone

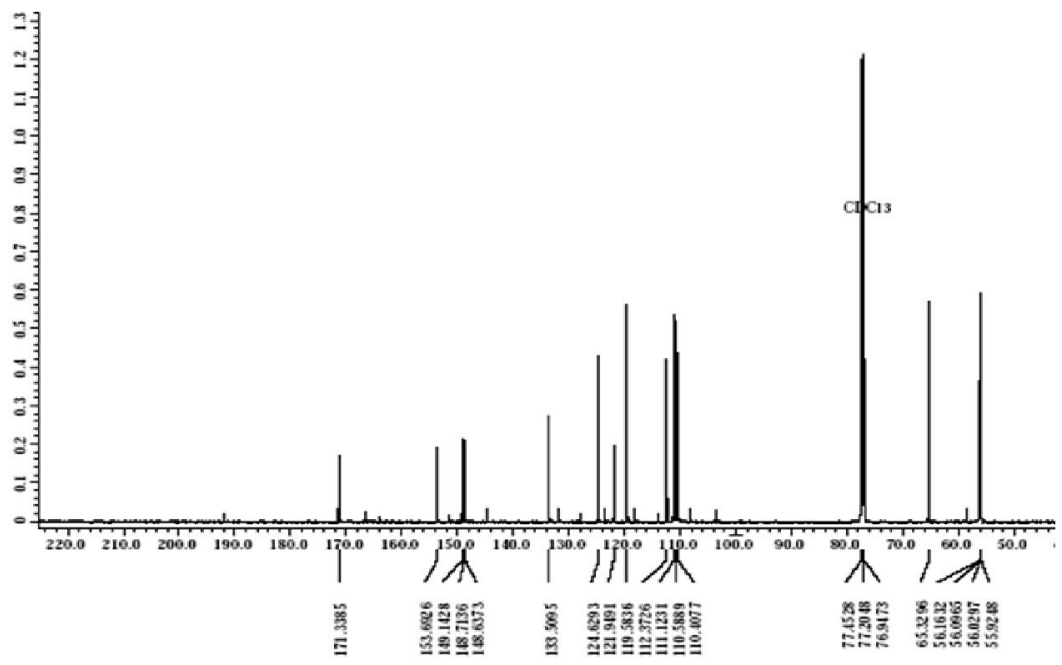

Figure $5 .{ }^{13} \mathrm{C}$ NMR Spectrum of 2',4'-dihydroxy-3,4-dimethoxychalcone

$\delta 7.7(1 \mathrm{H}, \mathrm{H}-\beta)$ corrresponding to $\mathrm{H}-\alpha$ and $\mathrm{H}-$ $\beta$. The three aromatic protons of the B-ring were observed at $\delta 6.90(1 \mathrm{H}, \mathrm{H}-5), \delta 6.91(1 \mathrm{H}$, H-2), $\delta 7.2$ (1H, H-6).

The ${ }^{13} \mathrm{C}-\mathrm{NMR}$ spectrum of chalcone (Figure 5) showed the presence of 17 different carbons. The signals for one carbonyl at $\delta 171$, and signals for methyl carbons at $\delta 56,0$. The spectrum indicated the presence six quarternary carbon at $\delta 153.6\left(\mathrm{C}-4^{1}\right), 149.1\left(\mathrm{C}-2^{1}\right), 148.7(\mathrm{C}-$ 4), 148.6 (C-3), 121.9 (C-1), $111.1\left(\mathrm{C}-1^{1}\right)$, and eight methine carbons at $\delta 133.5(\mathrm{C}-\beta), 119.5$ $(\mathrm{C}-\alpha), 124.6\left(\mathrm{C}^{-61}\right), 112.3$ (C-6), 110.5 (C-5), $110.4(\mathrm{C}-2), 65.3\left(\mathrm{C}-5^{1}\right), 56.1\left(\mathrm{C}-3^{1}\right)$, and two methoxy carbons at $\delta 56,02$. Based on the above spectral evidences, it can be concluded that compound (2) characterized as 2',4'dihydroxy-3,4-dimethoxy chalcone.

\section{2',5'-dihydroxy-3,4-dimethoxy chalcone}

The IR spectrum has the IR absorptions characteristics of hydroxy $\left(3410 \mathrm{~cm}^{-1}\right)$, aromatic $\mathrm{C}-\mathrm{H}\left(3062 \mathrm{~cm}^{-1}\right)$, aliphatic C-H $\left(2939 \mathrm{~cm}^{-1}\right)$, carbonyl $\mathrm{C}=\mathrm{O}\left(1674 \mathrm{~cm}^{-1}\right)$, alkenes $\left(1465 \mathrm{~cm}^{-1}\right)$, and $\mathrm{C}-\mathrm{O}\left(1026 \mathrm{~cm}^{-1}\right)$, functionalities. The ${ }^{1} \mathrm{H}-\mathrm{NMR}$ spectrum of 2',5'-dihydroxy-3,4dimethoxychalcone (Figure 6) explained the presence of two methoxyl groups in the B ring at $\delta 3.86$ and 3.87 , integrating for 12 protons. 


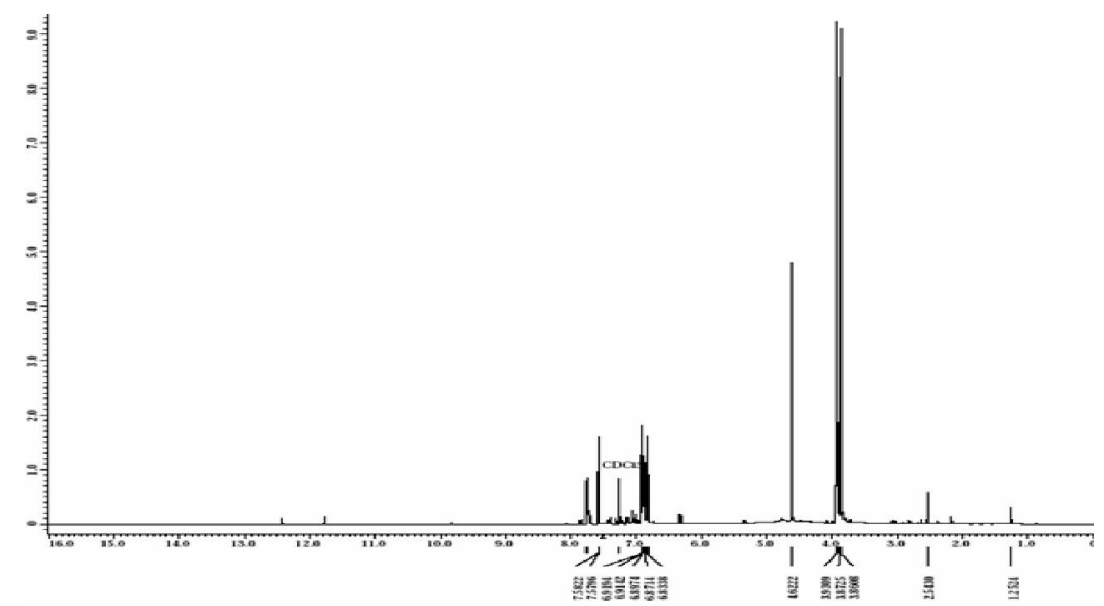

Figure 6. ${ }^{1} \mathrm{H}$-NMR spectrum of 2',5'-dihydroxy-3,4-dimethoxy chalcone

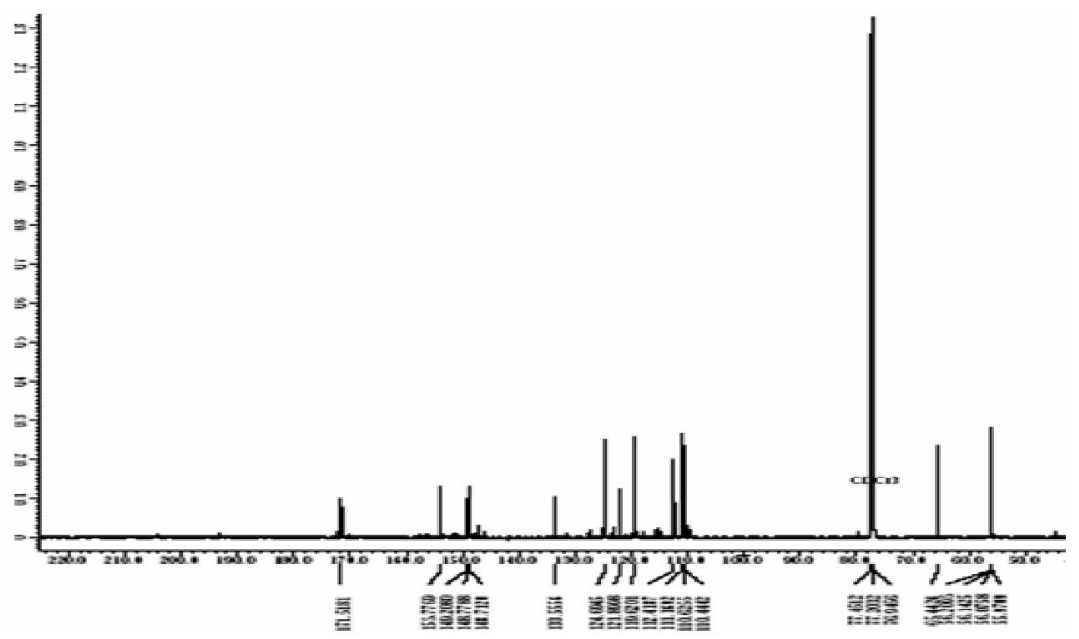

Figure 7. ${ }^{13} \mathrm{C}-\mathrm{NMR}$ spectrum of 2',5'-dihydroxy-3,4-dimethoxy chalcone

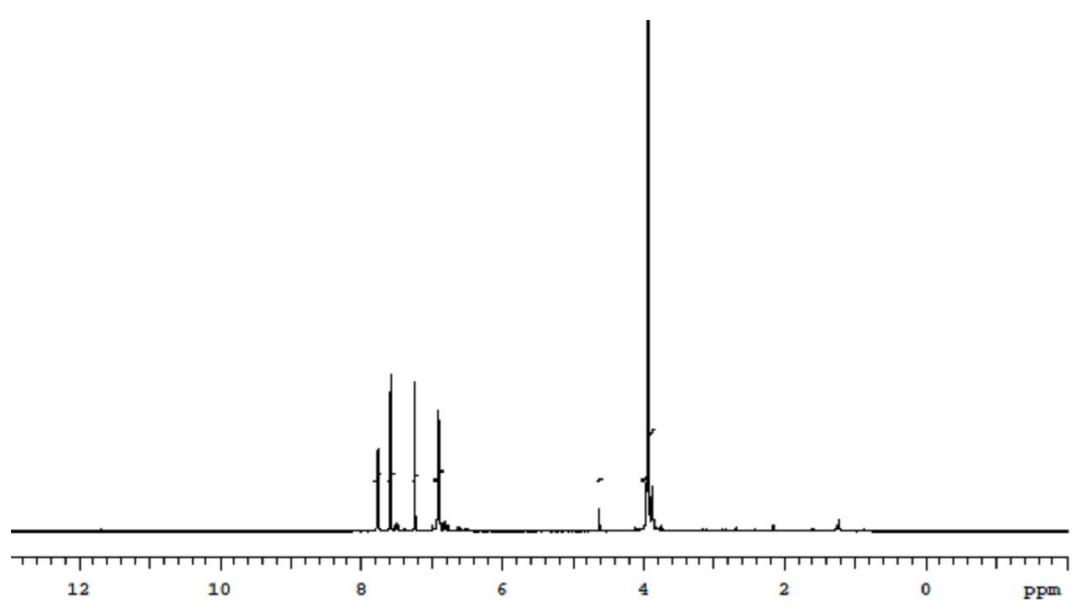

Figure 8. ${ }^{1} \mathrm{H}$-NMR spectrum of 2',6'-dihydroxy-3,4-dimethoxy chalcone 
The olefinic proton of $\alpha, \beta$-unsaturated ketone were clearly observed at $\delta 6.91(1 \mathrm{H}, \mathrm{H}-\alpha)$ and $\delta$ $6.92(1 \mathrm{H}, \mathrm{H}-\beta)$ corrresponding to $\mathrm{H}-\alpha$ and $\mathrm{H}-\beta$. The ${ }^{13} \mathrm{C}-\mathrm{NMR}$ spectrum of chalcone (Figure 7) showed the presence of 17 carbon with one carbonyl at $\delta 171.5, \delta 153.7,149.2,148.77$, 148.71, 133.5, 124.6, 121.8, 119.6, 112.4, 111.1, 110.6, 110.4, 65.4, 56.2, 56.1. The signals for methyl carbons were overlapping with each other at $\delta 56,0$ confirmed the presence of two methyl carbons. Based on the above spectral evidences, it can be concluded that compound (3) characterized as 2',5'-dihydroxy3,4-dimethoxy chalcone.

\section{2',6'-dihydroxy-3,4-dimethoxy chalcone}

The IR spectrum of the compound displayed streching bands for hydroxyl group at $3425 \mathrm{~cm}^{-1}$ and carbonyl group at $1674 \mathrm{~cm}^{-1}$. Its IR spectrum also showed bands for $\mathrm{C}-\mathrm{H}$ aliphatic at $2939 \mathrm{~cm}^{-1}, C=C$ group at $1427 \mathrm{~cm}^{-1}$, and $\mathrm{C}-0$ streching at $1026 \mathrm{~cm}^{-1}$. The ${ }^{1} \mathrm{H}-\mathrm{NMR}$ spectrum of the chalcone (Figure 8) explained the presence of two methoxyl groups in the $\mathrm{B}$ ring at $\delta 3.8$ and 3.9 integrating for 6 protons. The olefinic proton of $\alpha, \beta$-unsaturated ketone were clearly observed at $\delta 7.77(1 \mathrm{H}, \mathrm{H}-\alpha)$ and $\delta$ $7.75(1 \mathrm{H}, \mathrm{H}-\beta)$ corrresponding to $\mathrm{H}-\alpha$ and $\mathrm{H}-\beta$. Based on the above spectral evidences, it can be concluded that synthesized compound (4) characterized as 2',6'-dihydroxy-3,4-dimethoxy chalcone.

\section{Antioxidant activity}

In vitro antioxidant activity of the compounds synthesized was measured by DPPH methods, to determine the free radical scavenging activity. The DPPH radical scavenging activities of synthesized compounds were comparable to the activity of ascorbic acid. Ascorbic acid as a positive control gave IC50 $4.66 \mu \mathrm{g} / \mathrm{mL}$. The antioxidant activity data of the hydroxy chalcone (Table II) indicate that 2',5'-dihydroxy-3,4-dimetoksikalkon most active as a free-radical scavenging.

\section{CONCLUSION}

It could be concluded that four of hydroxy dimethoxy chalcone compounds (ie 2'-hydroxy-3,4-dimethoxy chalcone, 2',4'- dihydroxy-3,4-dimethoxy chalcone, 2',5'dihydroxy-3,4-dimethoxy chalcone, 2',6'dihydroxy-3,4-dimethoxy chalcone) can be synthesized from 3,4-dimethoxybenzaldehyde by Claisen-Schmidt condensation. The hydroxy dimethoxy chalcone synthesized were characterized by spectroscopic (IR, ${ }^{1} \mathrm{H}-\mathrm{NMR}$ and ${ }^{13} \mathrm{C}-\mathrm{NMR}$ ), indicating that the synthesis product has been formed. Synthesis of the hydroxy dimethoxy chalcone using grinding method is better than the conventional method. Measurement of antioxidant activity in vitro by DPPH method showed that only compound 2',5'-dihydroxy-3,4-dimethoxy chalcone active as an antioxidant.

\section{ACKNOWLEDGEMENT}

The authors are thankful to DP2M Dikti and Head of LPPM UNS, Rector of UNS and Dean of FKIP UNS, head of NMR Laboratory LIPI Jakarta, Organic Laboratory UGM, and Chemistry Laboratory PMIPA FKIP UNS.

\section{REFERENCES}

Belsare DP., Pal SC., Kazi AA., Kankate RS., and Vanjari SS., 2010, Evaluation of Antioxidant Activity of Chalcones and Flavonoids, Int. J. ChemTech Res., 2(2), 1080-1089.

Mandge S., Singh HP., Gupta D., and Moorthy HR., 2007, Synthesis and Characterization of some chalcone derivatives, Trend Applied Sci. Res., 2, 52-56

Nalwar YS., Sayyed MA., Mokle SS., Zanwar PR., and Vibhute YB., 2009, Synthesis and Insect Antifeedan Activity of Some New Chalcones Against Phenacocus solanopsis, World J. Chem., 4(2), 123-126

Narayana KR., Reddy MS., Chaluvadi MR., and Krishna RR., 2001, Bioflavonoids Classification, Pharmacological, Biochemical Effect and Therapeutic Potential , Ind J. Pharm., 33, 2-16

Patil CB., Mahajan SK., Katti SA., 2009, Chalcone: A Versatile Molecule, J. Pharm. Sci.Res., 1(3), 11-22

Prasad, Y. R., Lakshmana, A. R., and Rambabu, R., 2008, Synthesis and Antimicrobial Activity of Some Chalcone Derivatives, E-J. Chem., 5(3), 461-466 
Warner D., Sheng H., and Batini HI., 2004, Oxidants, Antioxidants and the Ischemic Brain. J. Exp. Biol., $207(18), 3221-3231$.

Wright JS., Johnson ER., and Dilabio GA., 2001, Predicting The Activity of Phenolic Antioxidants. Theoritical, Method, Analysis of Substituent Effect and Application to Major Families of
Antioxidants, J. Am. Chem. Soc., 123, 1173-1183

Zangade S., Mokle S., Vibhute A., Vibhute Y., 2011, An Efficient and Operationally Simple Synthesis of Some New ChalconesbyUsing Grinding Technique, Chem. Sci. J., 13, 1-6 